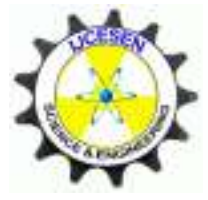

Copyright (C) IJCESEN
International Journal of Computationaland

Experimental $\boldsymbol{S}$ cience and $\boldsymbol{E N g i n e e r i n g}$

(IJCESEN)

Vol. 7-No.2 (2021)pp. 57-60

http://dergipark.org.tr/en/pub/ijcesen

ResearchArticle

\title{
Comparison of Mechanical Properties of Gypsum with and without Polypropylene Fibers
}

\author{
Xheneta ZENGO ${ }^{1}$, Bashkim ZIBERI ${ }^{2}$, Naim SYLA ${ }^{3}$ \\ ${ }^{1}$ Faculty of Natural Sciences and Mathematics, University in Tetovo, Ilinden str. n.n., 1200 Tetovo, North Macedonia \\ zengoxh@gmail.com - ORCID: 0000-0001-6122-0929 \\ ${ }^{2}$ Faculty of Natural Sciences and Mathematics, University in Tetovo, Ilinden str. n.n., 1200 Tetovo, North Macedonia \\ bashkim.ziberi@unite.edu.mk-ORCID: 0000-0001-9786-2595 \\ ${ }^{3}$ University of Prishtina, Department of Physics, 10000 Prishtina-KOSOVO \\ * Corresponding Author : naim.syla@ uni-pr.edu -- ORCID: 0000-0003-0857-4685
}

\section{Article Info:}

DOI: $10.22399 /$ ijcesen.798867

Received : 23 September 2020

Accepted : 13 May 2021

\section{$\underline{\text { Keywords }}$}

Gypsum,

Polypropylene,

Fibers,

Reinforcement.

\begin{abstract}
:
Gypsum is a mineral belonging to the group of sulfates, i.e., sulfuric acid, which is often found in Earth's crust. In this paper, two main types of gypsum, gypsum $\alpha$ and gypsum $\beta$, with different water content were prepared. Samples with and without polypropylene fibers, with different fiber content and different fiber lengths during preparation, produced in a gypsum factory located in the Debar region, North Macedonia, were studied. Physical properties such as density, porosity, water absorption capability and their kinetics, packing factor, hardening and others were examined using different methods. The main goal of this paper was the determination of mechanical properties of gypsum such as the compressive and flexure strength and the module of elasticity of the gypsum prisms. For the determination of elastic properties, the nondestructive method of ultrasound testing was used. In this test, the strength and quality of a prism is assessed by measuring the velocity of an ultrasonic pulse passing through a gypsum structure. This test is conducted by passing a pulse of ultrasonic wave through a prism and by measuring the time taken by the pulse to get through the structure. Higher velocities indicate good quality and continuity of the material, while slower velocities may indicate gypsum with many cracks or voids. The comparison of the obtained results from these two types of gypsum shows different mechanical and other physical properties.
\end{abstract}

\section{Introduction}

Gypsum is a mineral belonging to the group of sulfates, i.e., sulfuric acid, which is often found in the earth's crust. The gypsum chemical name is calcium sulfate dihydrate $\left(\mathrm{CaSO}_{4} \times 2 \mathrm{H}_{2} \mathrm{O}\right)$. In this paper, two main types hemihydrates, hemihydrate $\alpha$ and $\beta$, with three different water contents during preparation, were prepared and studied in the shape of prisms. The hemihydrate $(\mathrm{HH})$ is a crystalline hydrate containing one molecule of water for every two molecules of the compound in question.

These hemihydrates are reinforced to see if the properties of the gypsum change, aiming to obtain a much stronger material than gypsum itself. The polypropylene fibers used to reinforce the gypsum were 4,6,8 $\mathrm{mm}$ long and 18 micrometers thick. The mass of fibers used is $0.5 \%, 1 \%$ and $1.5 \%$ fibers of the mass of gypsum.[1][2][3]

Gypsum panels and blocks represent a good economical method for the manufacture' of partitions and walls, since the raw material cost as well as the labor cost are cheap, besides the ease of decoration. Their main drawbacks are the highwater permeability and their poor mechanical strength. In the present paper, polypropylene (PP) fibers were blended with plaster in an attempt to improve the properties of these products. It was found that the addition of PP fibers reduces the 
porosity, decreases the setting time and enhances the mechanical strength.

\section{Method}

Measurements were performed with prisms whose dimensions were $40 \mathrm{~mm} \times 40 \mathrm{~mm} \times 160 \mathrm{~mm}$. The prisms without fibers are constructed by mixing grinded gypsum who is calcined and turned into a hemihydrate, the grinded gypsum and a percentage of water, $40 \%$ for $\alpha$ and $60 \%$ for $\beta$ hemihydrate, are mixed together to form a homogeneous mass. For the samples that are reinforced with polypropylene fibers, the same mass if formed, with the same water factor, but now a percentage of fibers is going to be mixed into the mass. The percentage used is $0.5,1$ and $1.5 \%$ fibers of the mass of the gypsum. After the homogeneous mass is formed a mold in the same dimensions are filled with it, it is left to harden for 30 minutes, then the samples are ready to get out of the mold and to be left to dry for 24 hours in $40{ }^{\circ} \mathrm{C}$. The samples dried for 24 hours are tested in flexure, compression, ultrasound pulse velocity test, porosity etc.

Flexing:the method of placing the prism on three supporting points distanced equally from the center of the prism and the bending is going to occur on the center of the prism by pressing it until the prism reaches the maximal breaking point. The speed used is $0.5 \mathrm{~m} / \mathrm{s}$. The unit of the force needed to break the prisms is in $\mathrm{kN}$, while its tension in the scale of MPa or in $\mathrm{N} / \mathrm{mm}^{2}$.

Compression:presents the method of placing the prism between two parallel plates and pressing it with a force until it brakes. The unit of force for breaking the prism is in $\mathrm{kN}$, and the tension needed for breaking the prisms has values in $\mathrm{MPa}$ or $\mathrm{N} / \mathrm{mm}^{2}$.

The porosity: done when the prisms are completely dry, they are placed in a container with water covering completely the prismsfor 60 minutes, after they are removed, the water from the surface gets dried. The mass of each prism is taken. With the masses of the dry and the wet prisms it can be determined the porosity by using equation 1

$$
P=\frac{V_{p}}{V} \cdot 100 \%=\frac{\left(m_{d}-m_{w}\right) / \rho}{V} \cdot 100 \%
$$

Ultrasound pulse velocity test: In this test, the strength and quality of a prism is assessed by measuring the velocity of anultrasonic pulse passing through a gypsum structure. This test is conducted by passing a pulse of ultrasonic wave through prism to be tested and measuring the time taken by pulse to get through the structure. Higher velocities indicate good quality and continuity of the material, while slower velocities may indicate gypsum with many cracks or voids. Through this test the modulus of elasticity is determined using equation 2 [4][5]

$$
E=v^{2} \cdot \rho
$$

\section{Results}

From the experiments that were performed, the results were quite unexpectable. The porosity results obtained with the samples that contain $0 \%$ and $1 \%$ fibres that are $8 \mathrm{~mm}$ long, tested in both hemihydrates $(\mathrm{HH})$ with three different water factors for both of them.

\begin{tabular}{|c|c|c|c|}
\hline \multicolumn{4}{|c|}{ without fibers } \\
\hline $\mathbf{H H}$ & Wf & $0 \%$ fibers & $1 \%$ fibers \\
\hline \multirow{3}{*}{$\alpha$} & 0.40 & 22.64 & 22.65 \\
\hline & 0.425 & 24.02 & 24.03 \\
\hline & 0.45 & 25.87 & 25.87 \\
\hline \multirow{3}{*}{$\beta$} & 0.60 & 32.82 & 33.03 \\
\hline & 0.625 & 33.29 & 33.24 \\
\hline & 0.65 & 34.81 & 34.81 \\
\hline
\end{tabular}

Table 1. Change in porosity for the samples with and

As it can be seen, the porosity doesn't change even though fibres are added in the mixture (Table 1). That means that the gypsum can be used again in the same places as before, without absorbing more water, without loosing its function and purpose.

By the results in Table 2, it can be said that the longitudinal module of elasticity changes as we add fibres, but not uniformly. As the fibre percentage increases, most of the sample modules decrease, except for $\beta \mathrm{HH}$ which marks $7.05 \mathrm{GPa}$ when $1.5 \%$ fibers are added. It can be seen clearly that when we want to increase the module of elasticity, it is worth to use fibers that are $6 \mathrm{~mm}$ long. As for the mechanical behavior, when different percentage and different lengths of fibers are added into the mixture, the maximum breaking points change randomly, depending on what fiber works better in a certain $\mathrm{HH}$, or what length resists better in flexure and compression. The maximum breaking point in flexure, it increases when $1.5 \%$ fibers $8 \mathrm{~mm}$ long are mixed in both $\alpha$ and $\beta$ hemihydrates. In compression things change, because it is seen that for $\alpha \mathrm{HH}, 4 \mathrm{~mm}$ fibers work better, as for $\beta, 6 \mathrm{~mm}$ fibers create a better reinforcement, which mixture doesn't decrease the maximum breaking point. Even though, as it is seen in the tables 3 and 4, the maximum breaking point decreases when fibers are added into the mixture, the graph in Figure 1 shows that the sample gets destroyed after it reaches the maximum breaking point, as for the samples that 
have fibers in their content (Figure 2), it cracks after it reaches the maximum breaking point, but it doesn't get destroyed, it needs for about $25 \mathrm{MPa}$ more to detach the fiber connection. [6]

\section{Conclusion}

Based on the abovementioned results it can be concluded that even though the maximum breaking point decreases when fibres are added into the mixture, the gypsum get reinforced in a strong way even with a small amount of fibres in short lengths. These fibres can help to build much stronger constructions, by using gypsum, which is a very

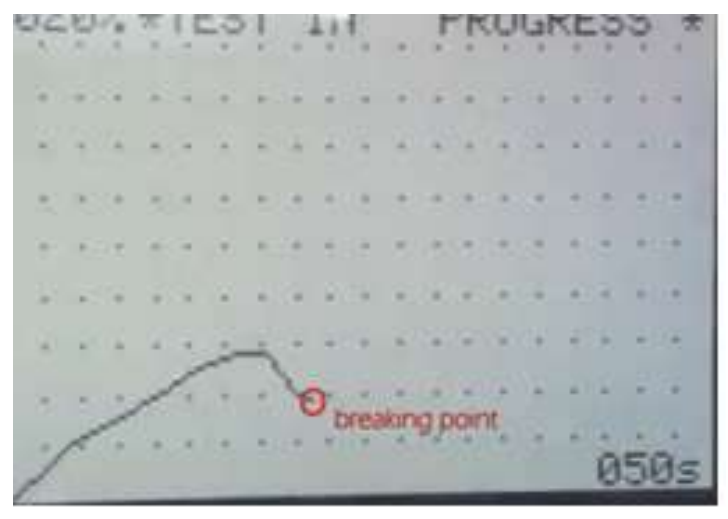

Figure 1. The sample without fibbers

economical and cheap solution. Adding fibres in the mixture won't even change the cost, because even PP fibres are cheap, it will cost $\$ 10$ for preparing 1 ton of prefabricated reinforced gypsum.

Table 2. Longitudinal module of elasticity for samples with and without fibres

\begin{tabular}{|c|c|c|c|c|c|c|}
\hline & \multicolumn{3}{|c|}{$\boldsymbol{\alpha} \mathbf{H H}, \mathbf{W f}=\mathbf{0 . 4 0}$ (GPa) } & \multicolumn{3}{c|}{$\boldsymbol{\beta} \mathbf{H H}, \mathbf{W f}=\mathbf{0 . 6 0}$ (GPa) } \\
\hline \%of fibers & $4 \mathrm{~mm}$ & $6 \mathrm{~mm}$ & $8 \mathrm{~mm}$ & $4 \mathrm{~mm}$ & $6 \mathrm{~mm}$ & $8 \mathrm{~mm}$ \\
\hline 0\% fibers & 13.85 & 13.85 & 13.85 & 6.95 & 6.95 & 6.95 \\
\hline $\mathbf{0 . 5 \%}$ fibers & 12.23 & 12.75 & 13.75 & 6.45 & 6.99 & 6.55 \\
\hline $\mathbf{1 \%}$ fibers & 11.79 & 13.15 & 12.65 & 6.80 & 6.77 & 6.62 \\
\hline $\mathbf{1 . 5 \%}$ fibers & 10.93 & 12.56 & 13.06 & 6.83 & 7.05 & 6.32 \\
\hline
\end{tabular}

Table 3. Maximum breaking point in flexure for samples with and without fibers

\begin{tabular}{|c|c|c|c|c|c|c|}
\hline & \multicolumn{3}{|c|}{$\boldsymbol{\alpha} \mathbf{H H}, \mathbf{W f}=\mathbf{0 . 4 0} \mathbf{( M P a )}$} & \multicolumn{3}{c|}{$\boldsymbol{\beta} \mathbf{~ H H}, \mathbf{W f}=\mathbf{0 . 6 0}$ (MPa) } \\
\hline \% of fibers & $4 \mathrm{~mm}$ & $6 \mathrm{~mm}$ & $8 \mathrm{~mm}$ & $4 \mathrm{~mm}$ & $6 \mathrm{~mm}$ & $8 \mathrm{~mm}$ \\
\hline 0\% fibers & 9.31 & 9.31 & 9.31 & 5.36 & 5.36 & 5.36 \\
\hline $\mathbf{0 . 5 \%}$ fibers & 1.68 & 7.77 & 5.26 & 3.56 & 0.95 & 4.23 \\
\hline $\mathbf{1 \%}$ fibers & 1.67 & 6.96 & 6.49 & 3.76 & 0.97 & 5.51 \\
\hline $\mathbf{1 . 5 \%}$ fibers & 1.95 & 7.27 & 10.38 & 2.92 & 1.16 & 6.95 \\
\hline
\end{tabular}

Table 4. Maximum breaking point in compression for samples with and without fibers

\begin{tabular}{|c|c|c|c|c|c|c|}
\hline & \multicolumn{3}{|c|}{$\boldsymbol{\alpha} \mathbf{H H}, \mathbf{W f}=\mathbf{0 . 4 0}(\mathbf{M P a})$} & \multicolumn{3}{c|}{$\beta \mathbf{H H}, \mathbf{W f}=\mathbf{0 . 6 0}(\mathbf{M P a})$} \\
\hline \% of fibers & $4 \mathrm{~mm}$ & $6 \mathrm{~mm}$ & $8 \mathrm{~mm}$ & $4 \mathrm{~mm}$ & $6 \mathrm{~mm}$ & $8 \mathrm{~mm}$ \\
\hline 0\% fibers & 30.33 & 30.33 & 30.33 & 13.63 & 13.63 & 13.63 \\
\hline 0.5\% fibers & 29.67 & 26.48 & 27.35 & 11.29 & 12.97 & 12.01 \\
\hline $\mathbf{1 \%}$ fibers & 27.71 & 26.22 & 23.01 & 10.79 & 12.77 & 10.79 \\
\hline $\mathbf{1 . 5 \%}$ fibers & 24.76 & 23.91 & 24.10 & 9.12 & 12.80 & 9.95 \\
\hline
\end{tabular}




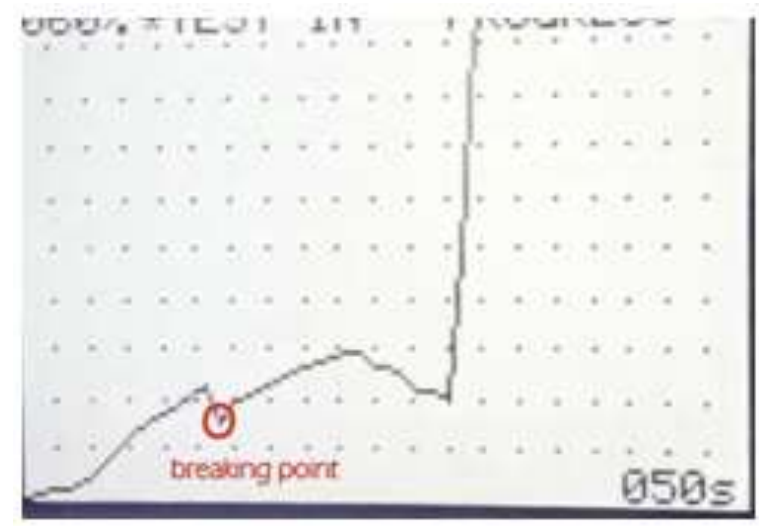

Figure 2. The sample with fibers

\section{Author Statements:}

- The authors declare that they have equal right on this paper.

- The authors declare that they have no known competing financial interests or personal relationships that could have appeared to influence the work reported in this paper

- The authors declare that they have nobody or nocompany to acknowledge.

\section{References}

[1]. F. E. S. S. L. L. P. J. Nilsson M, "Characterization of a novel calcium phosphate/sulphate bone cement," Journal of biomedical materials research , 2002

[2]. J. A. D. M. Gladis Camarini, "Gypsum hemihydrate-cement lends to improve renderings durability," Construction and Building Materials 25, 2011.

[3]. D. POWELL, "The $\alpha$ - and $\beta$-Forms of Calcium Sulphate Hemihydrate," Nature , pp. 185, 375376, 1960.

[4]. D. Ensiminger, Ultrasonic: fundamentals, technology, application, New York: Marcel Dekker, INC., 1988

[5]. K. Krautkramer, "Ultrasonic Testing of Materials," Springer-Verlag, 1969.

[6]. J. S. a. C. A. K.K. Kelley, Thermodynamic Properties of Gypsum and its Dehydration Products, Washington: Pp. iv. 73, 1941 